rises at the end of three minutes to $840^{\circ} \mathrm{C}$. Of course it is possible to reach temperatures of any degree up to the fusion of the wire.

I have found this, as already stated, to be extremely useful in conclucting several distillation tests with small charges of wood. It could be adapted for use as an ignition crucible by replacing the semi-spherical coil with wire wound as a cone and preparing cone-shaped asbestos pads to fit in the same. It would then be possible to use the apparatus for igniting limestones, cements, etc. It could, I believe, be equally as well adapted for the combustion of carbon from steel, since the carbon residue could be filtered upon an asbestos cone pad and placed in this coil, and by preparing the proper train of apparatus, a perfect combustion could be made. Its size and convenience and adaptability seem to me to promise much in this and similar uses.

\title{
THE DETERMINATION OF POTASH IN FERTILIZERS BY SUBSTITUTING MILK OF LIME FOR AMMONIA AND AMMONIUM OXALATE AS THE PRECIPITANT.
}

\author{
By C. L. Hare.
}

Received January 9, t903.

THE Lindo-Gladding method for the determination of potash in fertilizers possesses one particularly objectionable feature. The evaporation and ignition of an aliquot portion with sulphuric acid for the purpose of expelling ammonium salts and destroying dissolved organic matter is a tedious process and involves loss from spattering during evaporation.

A reliable modification which would exclude this feature would be highly desirable. At the sixteenth annual meeting of the Association of Official Agricultural Chemists, Ross presented a method based upon the use of barium carbonate as a precipitant for phosphates, iron, alumina, etc. He later suggested milk of lime as a precipitant and the writer in I9OI reported results obtained by collaborators on official methods for potash determinations.

The method employed is as follows: Weigh out to grams of the sample and boil with about $350 \mathrm{cc}$. of water for thirty minutes; while hot, add milk of lime till slightly alkaline. Cool, make up 
to $500 \mathrm{cc}$. with water and remove $50 \mathrm{cc}$., corresponding to I gram. Acidify with hydrochloric acid, add platinum solution and evaporate to soft dryness over the water-bath. The residue is then washed with 80 per cent. alcohol and ammonium chloride wash as in the Lindo-Gladding method.

In case of fertilizers containing organic matter, treat Io grams of the sample with dilute sulphuric acid (I:I) and incinerate; moisten the ignited mass with dilute sulphuric acid ( $I: I)$ and heat to aid in removing from the dish, boil with $350 \mathrm{cc}$. water and proceed as before. The milk of lime precipitates all lime except that present as sulphate and the solubility of the sulphate being only $I$ in 500 , the aliquot of $50 \mathrm{cc}$. will contain only o.I gram of that substance, an amount readily removed by the ammonium chloride wash-water and insufficient to cause material trouble either when the solution is made with water direct or after incineration with sulphuric acid. The potassium platinic chloride crystallizes well, and, after washing with alcohol, the salts of lime appear in light flakes which never require more than six washings with ammonium chloride wash for complete removal.

The modification possesses several advantages over the LindoGladding method: First, the precipitation of lime is immediate and there is no delay at this point; second, evaporation to expel ammonium salts is eliminated; third, probable loss of potash during the evaporation is obviated; Fourth, washing the potassium platinic chloride with alcohol and ammonium chloride wash may be performed thoroughly with greater ease and rapidity, while no larger amount of platinum is required than by the LindoGladding method. The accuracy of the method is evidenced by results as shown in the tables. It has been used by the writer upon several hundred samples of miscellaneous fertilizers as a check against the Lindo-Gladding method, but it is evident that the modification would not be applicable to fertilizers containing ammonium salts.

Table I gives parallel results by the milk of lime and the LindoGladding methods upon fertilizers containing no organic materials, the solution in each case being made by boiling the sample with water. 


\begin{tabular}{|c|c|c|c|c|c|}
\hline \multicolumn{6}{|c|}{ TABIE I. } \\
\hline $\begin{array}{l}\text { Lime. } \\
1.02\end{array}$ & $\begin{array}{l}\text { I,indo-Gladding. } \\
\text { I. } 29\end{array}$ & $\begin{array}{l}\text { Lime. } \\
\text { I. } 42\end{array}$ & $\begin{array}{l}\text { Lindo-Gladding. } \\
\qquad .62\end{array}$ & $\begin{array}{c}\text { Lime. } \\
4.5 I\end{array}$ & $\begin{array}{c}\text { Lindo-Glad ding. } \\
4.53\end{array}$ \\
\hline 2.33 & 2.20 & 1.91 & I.9I & 1.97 & I. 87 \\
\hline 2.42 & 2.42 & 1.95 & 2.12 & 2.54 & 2.64 \\
\hline 2.56 & 2.45 & 2.44 & 2.36 & 1.09 & 1.04 \\
\hline I. IO & 0.90 & 2.14 & 1.89 & 1.75 & 1.89 \\
\hline I. 66 & I. 88 & 1.76 & I. 88 & 2.59 & 2.44 \\
\hline I.40 & 1.65 & 0.84 & 0.80 & $4 \cdot 33$ & 4.53 \\
\hline 2.44 & 2.35 & $2.4 \mathrm{I}$ & 2.35 & 5.24 & 5.17 \\
\hline I. 58 & I. 73 & 2.29 & 2.09 & $0 . S_{1}$ & 0.98 \\
\hline 1.06 & 1.29 & 3.91 & 4.02 & 1.96 & 1.89 \\
\hline 2.59 & 2.63 & 2.46 & 2.46 & $4 \cdot 36$ & 4.47 \\
\hline 3.12 & 2.93 & 2.10 & 2.08 & 2.52 & 2.26 \\
\hline 2.II & 2.27 & 2.50 & 2.76 & 4.37 & $4 \cdot 33$ \\
\hline 2.49 & 2.74 & 1.75 & I. 89 & 1.95 & 1.66 \\
\hline 3.91 & $3 . \$ 6$ & I. 21 & 1.44 & 1.50 & 1.80 \\
\hline 1.49 & 1.32 & $5 \cdot 33$ & 5.65 & 2.16 & 2.00 \\
\hline 4.26 & 4.10 & $2.7^{2}$ & 2.76 & 2.49 & 2.76 \\
\hline $3.4 \mathrm{I}$ & 3.40 & $2.5 \mathrm{I}$ & 2.67 & $4.2 \mathrm{I}$ & 4.04 \\
\hline
\end{tabular}

Inspection of the tables reveals differences ranging from $O$ to 0.27 , with two exceptions, in a total of 60 samples. Of this number, 40 show differences less than 0.20 per cent. while the average difference is 0.10 per cent.

This average difference is, of course, without value as an indication of accuracy unless considered in connection with the variation of each pair of parallel determinations, but where so large a percentage of duplicates fall within the limits of probable etror, the average in differences of the entire number of determinations indicates in a measure the comparative accuracy of the two methods.

Considering that the figures in the tables represent first results and in no case a second determination by the same method, results by the milk-of-lime method appear quite as reliable as those obtained by the Lindo-Gladding. In the regular course of laboratory work duplicate determinations by one and the same method may easily show less closely agreeing results.

Table II shows parallel results obtained from fertilizers containing organic materials. The samples in each case were treated with dilute $(\mathrm{I}: \mathrm{I})$ stulphuric acid and incinerated before dissolving in water. 
DETERMINATION OF POTASH IN FERTILIZERS.

TABLE II.

$\begin{array}{lccccc}\text { Lime. } & \text { Lindo-Gladding. } & \text { Lime. } & \text { Lindo-Gladding. } & \text { Lime. } & \text { Lindo-Gladding. } \\ 2.16 & 2.2 \mathrm{I} & \mathrm{I} .87 & \mathrm{I} .84 & 2.58 & 2.53 \\ \mathrm{I} .7 \mathrm{I} & \mathrm{I} .70 & \mathrm{I} .3 \mathrm{I} & \mathrm{I} .5 \mathrm{I} & 2.13 & 2.24 \\ 2.27 & 2.39 & 2.46 & 2.48 & \mathrm{I} .48 & 1.49 \\ \mathrm{I} .35 & 1.08 & \mathrm{I} .59 & \mathrm{I} .60 & 2.07 & \mathrm{I} .80 \\ \mathrm{I} .51 & \mathrm{I} .50 & 2.49 & 2.38 & 2.37 & 2.60 \\ \mathrm{I} .92 & 1.98 & 1.66 & 1.70 & 2.59 & 2.45 \\ 2.33 & 2.38 & 2.09 & 2.1 \mathrm{I} & 2.12 & 1.96 \\ 3.46 & 3.33 & 1.59 & 1.57 & 2.73 & 2.59 \\ \mathrm{I} .32 & 1.46 & 2.37 & 2.10 & 2.7 \mathrm{I} & 2.6 \mathrm{I} \\ 2.65 & 2.53 & 2.16 & 2.20 & 2.6 \mathrm{I} & 2.89 \\ \mathrm{I} .62 & 1.82 & 2.66 & 2.42 & 2.38 & 2.08 \\ \mathrm{I} .97 & 1.78 & 1.16 & \mathrm{I} .20 & 2.44 & 2.63 \\ 2.20 & 2.29 & 3.22 & 3.1 \mathrm{I} & 2.2 \mathrm{I} & 2.13 \\ \mathrm{I} .3 \mathrm{I} & 1.3 \mathrm{I} & 2.4 \mathrm{I} & 2.28 & 2.28 & 2.33 \\ 3.67 & 3.46 & 3.38 & 3.36 & & \end{array}$

By reference to Table II we find variations ranging from o to 0.30 per cent. in a total of forty-four determinations. Thirty-four of these give differences of 0.20 per cent. or less, results averaging 0.06 per cent. higher by the lime method than by the LindoGladding.

Table III contains results from fertilizers containing organic materials. The samples were ignited with sulphuric acid ( $I: I$ ) before obtaining solutions for the lime method, while for the LindoGladding, solution was obtained by boiling the unignited sample with water.

TABLE III.

$\begin{array}{lccccc}\text { Lime. } & \text { Lindo.Gladding. } & \text { Lime. } & \text { Lindo-Gladding. } & \text { Lime. } & \text { Lindo-Gladding. } \\ \text { I.62 } & \text { I.66 } & 2.02 & 2.19 & \mathbf{2 . 1 4} & \mathbf{2 . I I} \\ 0.88 & 0.74 & \text { I.II } & \text { I.06 } & 1.82 & \text { 1.55 } \\ 1.53 & 1.63 & \text { I.6I } & 1.63 & 3.09 & 3.02 \\ 1.84 & 2.06 & 2.05 & 2.10 & 2.43 & 2.32 \\ 2.52 & 2.65 & 2.95 & 2.86 & 2.00 & 2.29 \\ 1.95 & 203 & 1.92 & 2.1 \mathrm{I} & 2.58 & 2.74 \\ 2.38 & 2.23 & 1.92 & 2.09 & 2.71 & 2.64 \\ 1.56 & 1.34 & 1.98 & 1.96 & 1.15 & 1.28 \\ 2.28 & 2.54 & 1.29 & 1.53 & 2.53 & 2.29 \\ 1.32 & 1.28 & 2.26 & 2.07 & 1.50 & 1.49 \\ 1.88 & 1.60 & 2.94 & 3.00 & 4.00 & 3.57 \\ 0.50 & 0.69 & 2.15 & 2.47 & 1.18 & 1.20 \\ 1.96 & 1.73 & 1.78 & 1.68 & 2.00 & 2.07 \\ 2.09 & 2.35 & 1.52 & 1.62 & 1.80 & 1.78 \\ 2.17 & 2.25 & 1.62 & 1.70 & 1.65 & 1.71\end{array}$




$\begin{array}{cccccc}\text { Lime. } & \text { Lindo-Gladding. } & \text { Lime. } & \text { Lindo-Gladding. } & \text { Lime. } & \text { Lindo-Gladding } \\ 2.38 & 2.43 & \text { I.83 } & \text { I.64 } & 2.63 & 2.37 \\ 2.88 & 2.60 & 2.24 & 2.21 & 2.97 & 2.94 \\ \text { I.43 } & 1.26 & 1.95 & 2.04 & 1.84 & 2.14 \\ 1.93 & 2.14 & 2.37 & 2.56 & 1.65 & 1.8 \mathrm{I} \\ 3.70 & 3.46 & 3.41 & 3.52 & 1.54 & 1.30 \\ 1.35 & 1.48 & 2.68 & 2.80 & 2.85 & 3.13 \\ 3.03 & 3.02 & & & & \end{array}$

These results show an extreme variation of 0.29 per cent. in a total of sixty-three determinations. Forty-six of the sixty-three vary less than 0.20 per cent. while the results average 0.02 lower by the lime method.

In Table IV may be found results on fertilizers containing organic materials. Solution for both methods was obtained by boiling the sample with water. The solutions for the lime method were considerably colored by dissolved organic matter.

TABLE IV.

\begin{tabular}{|c|c|c|c|c|c|}
\hline $\begin{array}{l}\text { Iime. } \\
\text { I.27 }\end{array}$ & $\begin{array}{l}\text { Liado-Gladding. } \\
\text { I.2 I }\end{array}$ & $\begin{array}{l}\text { Lime. } \\
\text { I.04 }\end{array}$ & $\begin{array}{c}\text { Lindo-Gladding. } \\
\text { I.I } 5\end{array}$ & $\begin{array}{l}\text { Lime. } \\
2.71\end{array}$ & $\begin{array}{c}\text { Lindo-Gladding } \\
2.61\end{array}$ \\
\hline I. 34 & I. 16 & I. 74 & 2.06 & 1.38 & I. $2 \mathrm{I}$ \\
\hline 2.37 & 2.44 & 2.65 & 2.35 & 2.28 & I. 83 \\
\hline $2.5^{\circ}$ & 2.54 & T. 28 & I. 25 & $2.4 \mathrm{~T}$ & 2.14 \\
\hline I. 48 & 1.08 & 1.79 & 1.71 & $5 \cdot 5^{\mathrm{I}}$ & $5.5 \mathrm{I}$ \\
\hline 5.03 & $4.6 \mathrm{I}$ & $2.0 \mathrm{I}$ & 1.92 & 2.40 & 2.I 8 \\
\hline 2.70 & 2.20 & 2.64 & 2.40 & 3.42 & $3.3^{8}$ \\
\hline 2.53 & 2.42 & 2.23 & I.80 & 2.35 & 2.49 \\
\hline $3.5^{\circ}$ & 3.05 & 2.69 & $2.3 \mathrm{I}$ & 2.15 & 2.18 \\
\hline I. 54 & 1.27 & 1.95 & 2.04 & 2.57 & 2.33 \\
\hline $2.5^{\circ}$ & 2.24 & 2. 19 & 2.14 & 2.II & 2. I I \\
\hline I. I6 & I. 20 & 2.43 & 2.45 & 1.09 & 0.99 \\
\hline 2.17 & 2.24 & 5.85 & 5.56 & 2.16 & I. 87 \\
\hline 2.30 & I. $8_{3}$ & 2.43 & 2.09 & 2.40 & 2.25 \\
\hline 1.00 & I.1O & $2.4 \mathrm{I}$ & I. 93 & 2.30 & 2. 10 \\
\hline
\end{tabular}

Although little was expected from the results obtained by the lime method under these conditions, still they show an extreme variation of only 0.55 per cent. in a total of forty-five determinations, while thirty of the forty-five differ less than 0.30 per cent., and the average difference is only 0.15 per cent. Nothing is claimed for the method when used under these conditions, but it is interesting to note that the method gives good results even when precipitation of platinum takes place in a solution considerably colored with organic matter. 